\title{
Disability Registration State of Children With Cerebral Palsy in Korea
}

\author{
Seong Woo Kim, $\mathrm{MD}^{1}$, Ha Ra Jeon, $\mathrm{MD}^{1}$, Yoon Kim, $\mathrm{MD}^{1}$, Soo Jin Choi, $\mathrm{MD}^{1}$, \\ Taemi Youk, $\mathrm{MS}^{2,3}$, Jiyong Kim, $\mathrm{MD}, \mathrm{PhD}^{4}$
}

\begin{abstract}
${ }^{1}$ Department of Physical Medicine and Rehabilitation, National Health Insurance Service Ilsan Hospital, Ilsan; ${ }^{2}$ Research Institute, National Health Insurance Service Ilsan Hospital, Ilsan; ${ }^{3}$ Department of Statistics, Korea University, Seoul; ${ }^{4}$ Department of Physical Medicine and Rehabilitation, Inje University Ilsan Paik Hospital, Ilsan, Korea
\end{abstract}

Objective To investigate the disability registration state of children with cerebral palsy (CP) in Korea.

Methods Based on the National Health Information Database, the disability registration state was examined for brain lesion disability and other possible complicated disabilities accompanying brain disorder in children diagnosed with CP aged up to 5 years old who were born between 2002 and 2008.

Results Of children diagnosed with $\mathrm{CP}, 73.1 \%$ were registered as having brain lesion disability for the first time before they turned 2 years old. The younger the children, the more likely they will have 1st and 2nd degree disability. However, when the age of children is increased, such likelihood is decreased. The percentage of children registered as having overlapping disabilities was $7 \%-20 \%$.

Conclusion It is important to establish a more accurate standard to rate disability and provide national support systems for children with CP with various severities and multiple disabilities. By reorganizing the current disability registration system for pediatric brain lesions, the system could serve as a classification standard to provide medical and social welfare services.

Keywords Cerebral palsy, Disabled children, Registries

\section{INTRODUCTION}

In 1990, Americans with Disabilities Act (ADA) was enacted to protect rights of the disabled. Currently, approximately 49 million Americans (15.4\% of the population) are protected by the ADA. The term 'disability' refers to a condition in which a person's daily life is limited due to physical or mental problem. A person who has a history of such problem is not considered to currently have disability because this person is not categorized as having any specific disorder or illness [1].

In Korea, the Welfare Law for Mentally and Physically

Received July 14, 2017; Accepted November 24, 2017

Corresponding author: Jiyong Kim

Department of Physical Medicine and Rehabilitation, Inje University Ilsan Paik Hospital, 170 Juhwa-ro, Ilsanseo-gu, Goyang 10380, Korea. Tel: +82-31910-7885, Fax: +82-31-910-7786, E-mail: halwayskim@gmail.com

ORCID: Seong Woo Kim (http://orcid.org/0000-0002-1548-8147); Ha Ra Jeon (http://orcid.org/0000-0002-4234-8086); Yoon Kim (http://orcid. org/0000-0002-7404-8432); Soo Jin Choi (http://orcid.org/0000-0001-6117-8353); Taemi Youk (http://orcid.org/0000-0002-4273-3777); Jiyong Kim (http://orcid.org/0000-0003-4693-8400).

@) This is an open-access article distributed under the terms of the Creative Commons Attribution Non-Commercial License (http://creativecommons.org/ licenses/by-nc/4.0) which permits unrestricted noncommercial use, distribution, and reproduction in any medium, provided the original work is properly cited. Copyright $\odot 2018$ by Korean Academy of Rehabilitation Medicine 
Disabled People was legislated for the first time in 1981. It was revised in 1989 and renamed the Act on Welfare of Persons with Disability. After several revisions, the current act has completed [2]. At the time of the enactment of the Welfare Law for Mentally and Physically Disabled People, only 5 types of disorders and illnesses were legally identified as disabilities (legal disabilities): physical disability, visual disability, hearing disability, speech and language disability, and intellectual disability. In the revision of 2000, the following 5 types of disability were added: brain lesion disability, developmental disorder, psychiatric disorder, kidney disease, and heart disease. Finally, the number of legal disability types is increased to 15 after 5 more categories (respiratory disorders, liver disease, facial disfigurement, intestinal and urinary stoma, and epilepsy) are added. Developmental disorder disability was renamed autism. According to the Disability Registration report published by the Ministry of Health and Welfare in the end of 2014, a total of 2,494,460 disabled people were registered in Korea, accounting for $4.8 \%$ of the total population [3].

In 1981, children with cerebral palsy (CP) were categorized as physically handicapped according to the Welfare Law for the Mentally and Physically Disabled People. $\mathrm{CP}$ was re-categorized in 1991 as a physical disability after revision of the Act on Welfare of Persons with Disabilities. The disability of brain lesion was established as a new category in the amendment of 2000, in which CP was recategorized $[3,4]$. Currently, the degree of brain lesion disability is rated from 1 to 6 , with 6 being the mildest. This rating system is based on the same standard for adults. Thus, such rating may not fully reflect disability characteristics of children. On the other hand, when a person has more than one type of disability, the condition is referred to as overlapping disabilities and the disability rating is determined according to the standard of combined disabilities (Ministry of Health and Welfare Notice No. 2015-188). In Korea, the Ministry of Health and Welfare regularly publishes statistics of the registration state of the disabled. It is difficult to collect specific information about the registry of children with CP since the registration statistics not only include $\mathrm{CP}$, but also includes other adult onset encephalopathies. Therefore, the aim of this study was to analyze the disability registration state of children with CP based on medical claims made to the National Health Insurance Service (NHIS).

\section{MATERIALS AND METHODS}

The NHIS gathers data for the National Health Information Database (NHID) for the entire population of Korea. The NHID consists of data of healthcare utilization, health screening, socio-demographic factors, and mortality. This study utilized data related to medical claims made to the NHIS between 2003 and 2013. Of infants born between January 1, 2002 and December 31, 2008, children with a history of at least two medical claims under CP diagnostic codes (Korean Standard Classification of Diseases [KCD]) at 2 years after birth were classified as $\mathrm{CP}$ cases. These cases were selected as subjects of this study. CP diagnostic codes are shown in Table 1. Only codes for KCD-6 are listed. However, in the actual study, codes from different time periods were considered. The type and degree of disability of children with CP were identified based on information provided by insurance qualifications. In this study, disability types related to CP including physical, brain lesion, visual, hearing, speech and language, intellectual, autism, and epilepsy were considered. The information on insurance qualifications refers to NHIS-registered information such as joining qualification of NHIS, address, qualification status, date of disqualification, and the type and degree of disability. This study reviewed the disability registration status of children up to 5 years old who were diagnosed with CP and born between 2002 and 2008.

\section{RESULTS}

A total of 13,591 children born between 2002 and 2008 were diagnosed with $\mathrm{CP}$. Among these, $61.3 \%$ were registered as having a disability by the age of 5 years. The most common type of disability for registration was brain

Table 1. CP diagnostic codes

\begin{tabular}{ll}
\hline Classification & \multicolumn{1}{c}{ KCD-6 } \\
\hline Spastic CP & G8000, 8001, 9002, 8008, 8009, 8100- \\
& $8103,8109-8113,8119,8190-8193$, \\
& $8199,830-833$ \\
Dyskinetic CP & G803 \\
Ataxic CP & G804 \\
Unspecified & G808 \\
\hline
\end{tabular}

CP, cerebral palsy; KCD-6, Korean Standard Classification of Diseases 6th edition. 
lesion, accounting for $70.4 \%$ of children with CP. This percentage did not change by year during the investigation period. An average of $18.1 \%$ of subjects were registered as having intellectual disability which was the 2 nd most common type. This percentage tended to decrease over time. Originally, children with $\mathrm{CP}$ were categorized as having a physical disability. After the introduction of brain lesion disability as a new disability type in 2000, children with $\mathrm{CP}$ were registered as having a brain lesion disability. The proportion of children registered as having a physical disability decreased from $4.1 \%$ of those born in 2002 to $2.3 \%$ of those born in 2008. Although some children with CP are still registered as having a physical disability, the percentage is gradually decreasing (Table 2).

We analyzed the percentage of children with $\mathrm{CP}$ who were registered as having a brain lesion disability accord-

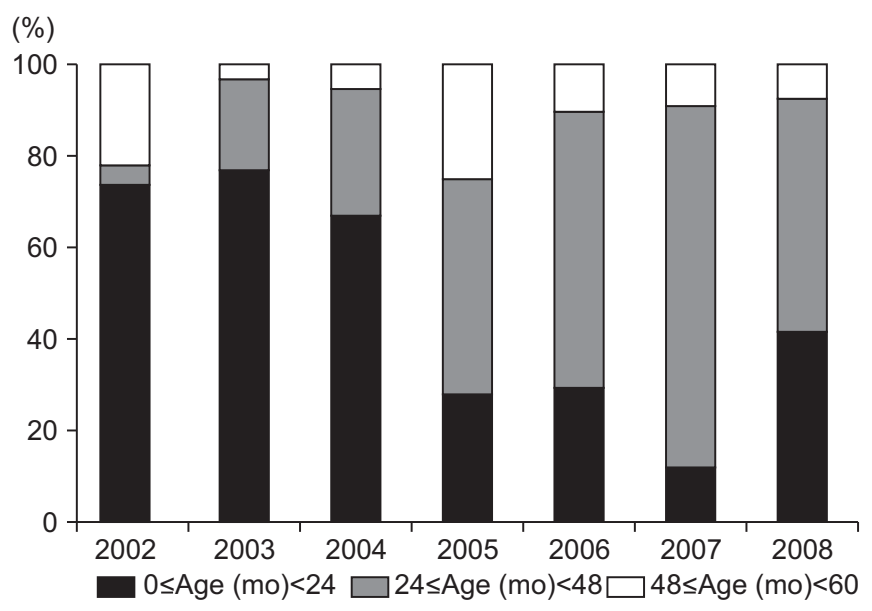

Fig. 1. Percentage of cerebral palsy children registered as having brain lesion disability by age. ing to their age. The proportion of children registered before 2 years of age continued to decrease up to 2007. It then seemed to increase in 2008. For children between ages of 2 and 4, this proportion showed an opposite trend (Fig. 1). In the first-time disability registration for brain lesion, $73.1 \%$ of children were registered by the age of 2 (Table 3). However, $67.60 \%$ of disabilities were rated as 1st degree disability regardless of first-time disability registration age. When first-time registration age increased, percentages of 1st and 2nd degree disabilities tended to decrease while those of 3rd-6th degree disabilities tended to increase (Fig. 2). To verify data of this study, we compared our results with those of the annual disability registration report published by the Ministry of Health and Welfare. Numbers of children registered as having a brain lesion disability before the age of 5 years were similar between the report $(3,166)$ and our data $(3,481)$ at the end of 2007.

CP can accompany not only a physical disability, but also other disabilities such as intellectual, visual, hearing, speech, and language. To acquire data for these accompanying disabilities, registrations of multiple overlap-

Table 3. First-time disability registration of brain lesion disability

\begin{tabular}{cc}
\hline Age $($ mo) & Number of children \\
\hline 0 and $<12$ & 1,240 \\
$\geq 12$ and $<24$ & 1,601 \\
$\geq 24$ and $<36$ & 1,449 \\
$\geq 36$ and $<48$ & 896 \\
$\geq 48$ and $<60$ & 542 \\
$\geq 60$ and $<72$ & 140 \\
\hline
\end{tabular}

Table 2. Disability registration by year

\begin{tabular}{ccccccc}
\hline $\begin{array}{c}\text { Birth } \\
\text { year }\end{array}$ & $\begin{array}{c}\text { Children diag- } \\
\text { nosed with CP }\end{array}$ & $\begin{array}{c}\text { Children regis- } \\
\text { tered as disability }\end{array}$ & $\begin{array}{c}\text { Brain lesion } \\
\text { disability }^{\text {a) }}\end{array}$ & $\begin{array}{c}\text { Physical } \\
\text { disability }^{\text {a) }}\end{array}$ & $\begin{array}{c}\text { Intellectual } \\
\text { disability }^{\text {a) }}\end{array}$ & $\begin{array}{c}\text { Autistic } \\
\text { disability }^{\text {a) }}\end{array}$ \\
\hline 2002 & 2,035 & $1,495(73.5)$ & $961(64.3)$ & $62(4.1)$ & $348(17.1)$ & $59(2.9)$ \\
\hline 2003 & 1,997 & $1,364(68.3)$ & $894(65.5)$ & $66(4.8)$ & $293(14.7)$ & $45(2.3)$ \\
\hline 2004 & 1,865 & $1,254(67.2)$ & $839(66.9)$ & $43(3.4)$ & $269(14.4)$ & $58(3.1)$ \\
\hline 2005 & 1,944 & $1,171(60.2)$ & $863(73.7)$ & $51(4.4)$ & $161(8.3)$ & $39(2.0)$ \\
\hline 2006 & 1,894 & $1,064(56.2)$ & $807(75.8)$ & $27(2.5)$ & $150(7.9)$ & $23(1.2)$ \\
\hline 2007 & 2,039 & $1,114(54.6)$ & $811(72.8)$ & $34(3.1)$ & $181(8.9)$ & $27(1.3)$ \\
\hline
\end{tabular}

Values are presented as number (\%).

$\mathrm{CP}$, cerebral palsy.

${ }^{\text {a) }}$ These refer to children registered for each type of disability, including cases of overlapping disability. 
ping disabilities were analyzed. Cases of visual, hearing, speech and language, intellectual, autistic, and epilepsy disabilities registered as accompanying a brain lesion disability were examined. In the case of only one disability accompanying brain lesion disability, intellectual disability was the most common (Table 4). The percentage of children registered as having overlapping disabilities of brain lesion and intellectual disability increased from $12.2 \%$ for children born in 2002 to $17.3 \%$ for children born in 2004. Since 2004, this percentage gradually decreased to $5.6 \%$ for children born in 2008 . Only $0.1 \%$ of children born in 2002 showed speech and language disability accompanying brain lesion disability. This

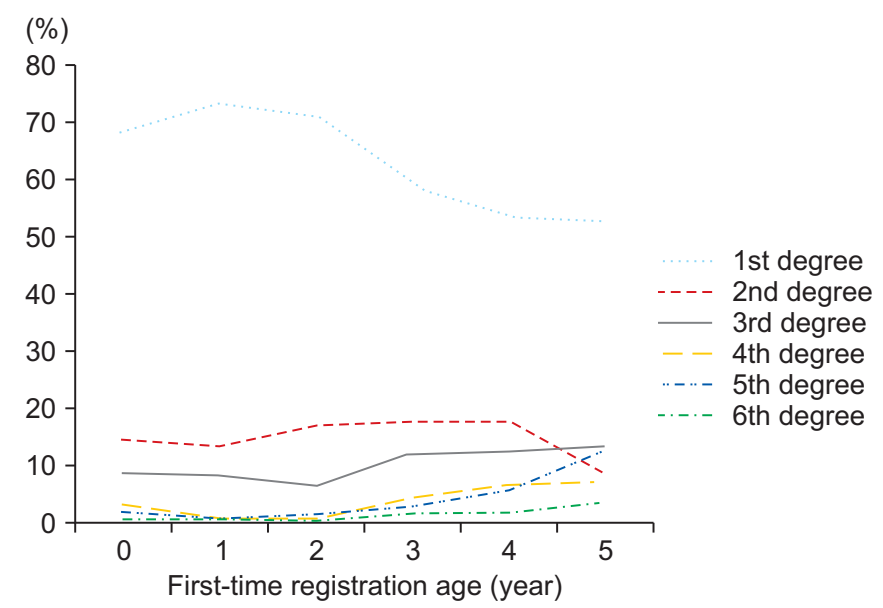

Fig. 2. Brain lesion disability registration state according to the degree of disability and first-time registration age. Degree of brain lesion disability is rated from 1st to 6th, with 6 th being the mildest. Age $0(\geq 0$ and $<12 \mathrm{mo}$ ), age 1 ( $\geq 12$ and $<24 \mathrm{mo}$ ), age $2(\geq 24$ and $<36 \mathrm{mo}$ ), age 3 ( $\geq 36$ and $<48 \mathrm{mo}$ ), age 4 ( $\geq 48$ and $<60 \mathrm{mo}$ ), and age 5 ( $\geq 60$ and $<72)$. percentage gradually increased to $0.9 \%$ for those born in 2008. Other disabilities did not show any clear tendency. Some children registered two overlapping disabilities along with brain lesion disability, including cases of intellectual disability with autistic disability or intellectual disability with speech and language disability. However, according to the current rating guidelines for the degree of disability, the above two cases were excluded from the overlapping disability category. Thus, these cases were considered as registry errors.

\section{DISCUSSION}

$\mathrm{CP}$ is a neurodevelopment disorder caused by damage to the developing brain. It impacts patients throughout their life [5]. It is widely known that children with CP can survive through adulthood $[6,7]$. When their survival rate improves, concerns regarding their social costs are also increased. In a previous study, Eunson [8] has reported that direct and indirect cost for a CP patient is approximately US $\$ 900,000$. Kruse et al. [9] has classified lifetime cost of CP patient into three categories: healthcare cost, productivity cost, and social cost. The calculated total cost was reported to be US $\$ 990,000$ for male CP patient add US $\$ 921,000$ for female CP patient [9]. Since a large social cost is spent throughout the life of a CP patient, precise data of CP registry is very important for planning health and welfare related social policy [9]. In Korea, the Ministry of Health and Welfare regularly publishes statistics of the disability registration state. However, it is difficult to collect specific information about the registry of children with $\mathrm{CP}$ since the registration statistics not only includes CP, but also includes other adult onset encephalopathies. Therefore, considerable effort was made in this

Table 4. Overlapping disability registration of children with brain lesion disability

\begin{tabular}{ccccccc}
\hline Birth year & Intellectual & Autistic & Visual & Hearing & $\begin{array}{c}\text { Speech and } \\
\text { language }\end{array}$ & Epilepsy \\
\hline 2002 & $117(12.2)$ & $6(0.6)$ & $2(0.2)$ & $4(0.4)$ & $1(0.1)$ & $3(0.3)$ \\
2003 & $120(13.4)$ & $2(0.2)$ & $3(0.3)$ & $4(0.4)$ & $1(0.1)$ & $5(0.6)$ \\
\hline 2004 & $145(17.3)$ & $7(0.8)$ & $6(0.7)$ & $4(0.5)$ & $0(0.0)$ & $0(0.0)$ \\
2005 & $113(13.1)$ & $4(0.5)$ & $7(0.8)$ & $5(0.6)$ & $1(0.1)$ & $0(0.0)$ \\
2006 & $86(10.7)$ & $4(0.5)$ & $2(0.2)$ & $1(0.1)$ & $4(0.5)$ & $0(0.0)$ \\
\hline 2007 & $79(9.7)$ & $3(0.4)$ & $5(0.6)$ & $2(0.2)$ & $0(0.0)$ & $3(0.4)$ \\
\hline 2008 & $39(5.6)$ & $1(0.1)$ & $1(0.1)$ & $3(0.4)$ & $6(0.9)$ & $0(0.0)$ \\
\hline
\end{tabular}

Values are presented as number $(\%)$. 
study to gather detailed information about $\mathrm{CP}$ in children based on the government statistics. A significant result was obtained in this study based on medical claim data of the entire national population from the NHIS despite the lack of pre-existing data on the disability registration state for pediatric $\mathrm{CP}$.

Results of this study showed that more than $70 \%$ (73.1\%) of children with $\mathrm{CP}$ were registered for the first time as early as 2 years of age. A similar trend was found in the reported statistics from the Ministry of Health and Welfare. In the overall disability registration state, the number of children with physical, visual, hearing, speech and language, and intellectual disabilities increased during the early elementary school period. On the other hand, the number of children registered with brain lesion disability increased from the age of 1 [10]. When the disability rating criteria were revised in 2009 , children and adolescents could be registered with brain lesion disability from the age of 1 . However, prior to the 2009 revision, the age at which brain lesion disability was assessed was not specified. As time passed, the proportion of registration for children aged 24-48 months was increased than that in earlier registration data. Since this study was conducted before the revision of the disability rating criteria, such increase might be less related to the revision. However, since the proportion of severe CP has decreased over time, the need for early disability registration might be decreasing.

The majority of patients $(67.6 \%)$ were rated as 1 st degree of disability at the time of first registration. As the first-time registration age increased, 3rd-6th degree rating tended to increase. However, the 1st degree is the most common group. Thus, the degree of disability does not properly reflect the severity of CP disability. Today, the degree of $\mathrm{CP}$ is rated according to the level of strength in upper and lower extremities and the level of independence and performance in walking and daily activities using the Modified Barthel Index (MBI). However, these criteria are based on adult brain lesion disability. They do not reflect characteristics of pediatric brain lesion disability. As seen in results of this study, most children are registered for the first time before the age of 2 , at which stage even normally developing children need considerable support from their caregivers in their daily activities. Therefore, the severity of disability cannot be determined according to independent performance of daily activities.
The degree of disability can also alter as a child grows. If these characteristics specific to neurodevelopment disorders are not considered, it is difficult to correctly distinguish the degree of disability in children. To address this limitation, the rating guidelines of the degree of disability were partially revised in 2013 (Ministry of Health and Welfare Notice No. 2013-56) where the Gross Motor Function Classification System, Gross Motor Function Measure, and Bayley Scales of Infant Development were used for brain lesion disability rating in children aged 1 to 7. Although there are no specific standards for determining the degree of disability by integrating all evaluations, it is critical to provide a systematic basis with differentiated rating standards for children that are different from the adult disability rating system.

Children with CP can suffer various medical problems associated with movement and posture along with intellectual disability and sensory disabilities such as hearing and visual disabilities [5]. A study by Kirby et al. [11] on 8-year-old children with CP showed that $35 \%$ of children with CP also had epilepsy of various severities. According to a report on the status of disabled people published by the Korea Institute for Health and Social Affairs in 2014 [12], 7.1\% of children with CP had epilepsy. This number significantly differed from the result of the present study which showed $0.0 \%-0.6 \%$ of children were registered as having overlapping epilepsy disability each year. Also, according to that report [12], of all children registered with CP who also had an overlapping disability, $49.8 \%$ had speech and language disability, $23.4 \%$ had intellectual disability, $15.7 \%$ had visual disability, and $11.7 \%$ had hearing disability. These results differed from those of the present study in which the status of overlapping disabilities was analyzed for children up to 5 years old. This implies that accompanying disabilities such as speech and language or intelligence might become more severe as children age. Since only one type of disability is usually registered in the current system, it is difficult to determine the exact duplication of the overlapping disability status. Voorman et al. [13] have reported that social function and communication of $\mathrm{CP}$ patients are limited when they have additional seizures or speech and language disabilities. Tan et al. [14] have studied CP patients aged from 1 to 24 years and found that, for patients who have the same motor function, CP patients with overlapping intellectual disability show less social participation. Simi- 
larly, Fauconnier et al. [15] have reported that patients who suffer accompanying pain, visual impairment, and eating disorders show decreased social participation. As seen in these studies, when a CP patient has accompanying disabilities other than physical impairment, even if the disability is mild, the patient shows restricted daily activities and social participation. Even if the severity of physical impairment from CP is mild, when the number of accompanying disabilities increases, the severity of the degree of overall disability also increases. However, the current disability rating regime lacks a system to reflect these overlapping disability issues appropriately. Thus, it is impossible to distinguish between CP children with complicated multiple problems and CP children without overlapping problems through current disability registry data. It is impossible to determine those children who need more help from a social welfare point of view either. For this reason, a more sophisticated disability registration system for $\mathrm{CP}$ is needed.

Our study has several limitations. First, some CP children might be excluded because subjects of the present study were determined based on medical claims under CP diagnostic codes. These data are thus limited to data of the NHID. However, at present, it is impossible to investigate the status of disability registration except for the use of observational studies using the national big data. A prospective study using a Korean CP cohort is needed in the future. Second, our data were restricted to children born between 2002 and 2008 based on medical claims from 2003 to 2013. Third, analysis of the later data collected after the tracking period was limited since the observation period of the data was restricted to the age of 5 . Under the current Welfare of Persons with Disability Act, patients diagnosed with brain lesion disability before the age of 6 are required to be re-evaluated at an age between 6 and 12. As the degree of brain lesion disability may change when children age, the progress of disabilities needs to be analyzed according to increase of tracking period.

In conclusion, the aim of this study was to analyze the disability registration state of children with $\mathrm{CP}$ in their infant and pre-elementary school periods based on NHID. Our results showed that the current disability registration system did not accurately reflect the severity or assess the complex associated problems of children with CP. By reorganizing the disability registration system for pediatric brain lesions, it might serve as a classification standard to provide medical and social welfare services for $\mathrm{CP}$ patients.

\section{CONFLICT OF INTEREST}

No potential conflict of interest relevant to this article was reported.

\section{ACKNOWLEDGMENTS}

This study was supported by a grant (No. NHIS-2017-1225) from the National Health Insurance Ilsan Hospital. This study used NHIS-NSC data (No. NHIS-2017-1-225) collected by the National Health Insurance Service.

\section{REFERENCES}

1. Gostin LO. The Americans with Disabilities Act at 25: the highest expression of American values. JAMA 2015;313:2231-5.

2. Kim S. The disabled welfare act revision bill and its significance. Health Welf Policy Forum 2007;127:3440.

3. Hwang SK. Understanding the new international classification of disability and introduction of the concept of functional disability. Q J Labor Policy 2004;4:12849.

4. Kim M, Lee I. The effect of functional status and personal assistance services uses on perceived independence among people with physical disabilities. J Korean Social Welf Adm 2007;20:53-83.

5. Bax M, Goldstein M, Rosenbaum P, Leviton A, Paneth N, Dan B, et al. Proposed definition and classification of cerebral palsy, April 2005. Dev Med Child Neurol 2005;47:571-6.

6. Bottos M, Feliciangeli A, Sciuto L, Gericke C, Vianello A. Functional status of adults with cerebral palsy and implications for treatment of children. Dev Med Child Neurol 2001;43:516-28.

7. Hutton JL, Pharoah PO. Effects of cognitive, motor, and sensory disabilities on survival in cerebral palsy. Arch Dis Child 2002;86:84-9.

8. Eunson P. The long-term health, social, and financial burden of hypoxic-ischaemic encephalopathy. Dev Med Child Neurol 2015;57 Suppl 3:48-50. 
9. Kruse M, Michelsen SI, Flachs EM, Bronnum-Hansen $\mathrm{H}$, Madsen M, Uldall P. Lifetime costs of cerebral palsy. Dev Med Child Neurol 2009;51:622-8.

10. Ministry of Health and Welfare. Disabled Enrollment. Sejong: Ministry of Health and Welfare; 2014.

11. Kirby RS, Wingate MS, Van Naarden Braun K, Doernberg NS, Arneson CL, Benedict RE, et al. Prevalence and functioning of children with cerebral palsy in four areas of the United States in 2006: a report from the Autism and Developmental Disabilities Monitoring Network. Res Dev Disabil 2011;32:462-9.

12. Kim S, Lee Y, Hwang J, Oh M, Lee M, Lee N, et al. Survey of disabled persons 2014. Sejong: Ministry of Health and Welfare; 2014.

13. Voorman JM, Dallmeijer AJ, Van Eck M, Schuengel C,
Becher JG. Social functioning and communication in children with cerebral palsy: association with disease characteristics and personal and environmental factors. Dev Med Child Neurol 2010;52:441-7.

14. Tan SS, Wiegerink DJ, Vos RC, Smits DW, Voorman JM, Twisk JW, et al. Developmental trajectories of social participation in individuals with cerebral palsy: a multicentre longitudinal study. Dev Med Child Neurol 2014;56:370-7.

15. Fauconnier J, Dickinson HO, Beckung E, Marcelli M, McManus V, Michelsen SI, et al. Participation in life situations of 8-12 year old children with cerebral palsy: cross sectional European study. BMJ 2009;338:b1458. 